\title{
A Sociedade de Riscos na Crise de suas Representações: as percepções ambientais de professores do Ensino Básico
}

Guilherme Henrique Almeida Pereira

Fernando Mendes Guerra

Lana Cláudia de Souza Fonseca

Bruno Barçante Ladvocat Cintra

\section{RESUMO}

A SOCIEDADE DE RISCOS NA CRISE DE SUAS REPRESENTAÇÕES: AS PERCEPÇÕES AMBIENTAIS DE PROFESSORES DO ENSINO BÁSICO.

As práticas pedagógicas na escola não contemplam problematizações das reais causas da crise socioambiental. Assim, a realização de processos formativos de Educação Ambiental com professores é um caminho a ser explorado. Esta pesquisa objetivou identificar representações ambientais de professores e inferir o reflexo das representações observadas sobre a compreensãoação desse grupo e suas práticas pedagógicas. O caminho metodológico se deu pela adaptação de uma oficina que visa a estimular a desconstrução/reconstrução conceitual acerca de percepções socioambientais. As representações iniciais dos professores foram orientadas por perspectiva ampla e distante de concepção naturalista. Entretanto, ao longo da oficina, observou-se que as representações se relacionaram a dimensões cartesianas e antropocêntricas. Esse contrassenso revelou como a compreensão-ação dos professores está atrelada a um modelo paradigmático de separação entre os meios social e ambiental. Isso demonstrou a hegemonia desse modelo e ratificou a força que ele exerce nas instituições sociais, especialmente as de ensino, como a escola. Palavras-chave: paradigmas da disjunção; crise socioambiental; formação de professores.

\section{ABSTRACT}

A SOCIETY OF RISKS IN THE CRISIS OF THEIR REPRESENTATIONS: THE ENVIRONMENTAL PERCEPTIONS OF TEACHERS IN THE BASIC EDUCATION.

The pedagogical practices in the School do not address the real causes of social and ecological crisis. Therefore, the realization of the formation processes of Environmental Education with teachers is a way to explore. The objective was to identify environmental representations of teachers and infer the impact of these representations on action and understanding of this group and their practices. The methodological approach was a workshop that aims to encourage 
the conceptual deconstruction/ reconstruction insights about society and environment. The representations of the teachers were distant from a naturalistic perspective. However, it was found that the representations are related to Cartesian and anthropocentric dimensions. This contradiction has revealed how the understanding is tied to a paradigmatic model of separation between the social and the ecological. This demonstrated the dominance of this model and ratified the force it exerts on social institutions, especially education, as the School. Key words: paradigms of disjunction; ecological and social crisis; teacher training.

\section{INTRODUÇÃO}

Desde o final do século passado, a conservação da biodiversidade é um dos maiores desafios que se impõe à humanidade, devido aos elevados níveis de perturbações antrópicas sobre os ambientes naturais (VIANA \& PINHEIRO, 1998). As florestas e outros ecossistemas são convertidos em terras produtivas, para geração de lucros, e as espécies são caçadas para consumo pessoal, comércio e lazer (PRIMACK \& RODRIGUES, 2001, p.89). O desmatamento e o uso do solo de forma cada vez mais intensa, para produção madeireira ou para o cultivo agrícola, têm depauperado os ambientes (PRIMACK \& RODRIGUES, 2001, p.89). Florestas quando são queimadas e convertidas em pastagens permanentes têm os solos conduzidos à total degradação. Isso, além de degradar as florestas, compromete o próprio sistema produtivo, pois o torna insustentável (LEPSCH, 2002).

Diante desse cenário, a "questão ambiental" tem crescido nas últimas décadas e ganhado novas dimensões. Uma determinada indústria cultural, que enxerga com clareza a penetração das questões ambientais nos diversos segmentos da sociedade, tem transformado essas questões em mercadoria (GUERRA, 2008; LADVOCAT, 2009). Mudanças climáticas, aquecimento global e extinção de espécies, por exemplo, são temas bastante presentes em nosso cotidiano, veiculados por diferentes mídias em propagandas de diversos produtos que consumimos no dia a dia. Em função dessa expansão da questão ambiental, há um reconhecimento na sociedade quanto à preocupação com a degradação dos ambientes naturais associada a temas como a perda de espécies. Entretanto, a questão não é puramente ecológica e não se relaciona exclusivamente aos impactos antrópicos causados aos ecossistemas naturais. Juntamente com outros temas como poluição, miséria e fome, os problemas que denominamos ambientais resultam da maneira como nos relacionamos com os demais elementos da natureza nas últimas décadas e, em especial, nos dias atuais. 
Os "problemas ambientais" manifestam um conflito entre os interesses privados e um recurso de propriedade comum (GUIMARÃES 2006, p.17), que representam bens de toda a sociedade, como o ar puro, água limpa e qualidade do solo (PRIMACK \& RODRIGUES, 2001, p.39). Nesse sentido, tudo o que culturalmente tratamos como sendo problemas ambientais são, na realidade, consequências que identificam a eminência da crise ambiental que aflige a humanidade. Uma crise que não é fruto do acaso, mas resultante dos tipos de relações que construímos entre nós e com os demais elementos da natureza (GUERRA, 2008; GUIMARÃES, 2006, p.18), em uma sociedade que tem sido denominada "sociedade de riscos" na qual os riscos enfrentados não são mais os fenômenos naturais, mas sim os riscos produzidos por ela própria (GUIMARÃES, 2006, p.19).

Dessa forma, encarar o produto de nossas relações com os demais elementos da natureza como sendo problemas a mbientais é incorrer no erro. Ao enfatizar a dimensão ecológica em detrimento de outras contextualizações, essa representação promove o entendimento da estrutura e funcionamento dos ambientes naturais, mas ignora a interface destes com a dinâmica social (LOUREIRO, 2004, p.12). No entanto, isso pode encerrar um tratamento acrítico da crise e resultar em ações insustentáveis no tempo. Para além da dimensão puramente ecologista, a crise ambiental caracteriza-se por uma intrincada teia de elementos e processos que permeiam tanto os ambientes naturais, quanto o meio de convívio das sociedades humanas e seu modelo de desenvolvimento sócio-ideológico-políticoeconômico. A crise vincula-se às diferenças de classes, aos hábitos de consumo, a problemas de habitação e saneamento básico, dentre outras questões relacionadas ao sistema capitalista que tornam o viver a cada dia mais insustentável. É uma crise socioambiental.

Essa crise, ainda hoje, está atrelada a algumas percepções de mundo muitas vezes limitadas e, porque não dizer, equivocadas. Uma dessas se relaciona à percepção de "meio ambiente" que, em geral, é visto como sinônimo de "natureza" e externo à nossa existência. Ao perguntarmos a um grupo de leigos o que para eles é meio ambiente, é possível que as respostas não sejam muito diferentes de: 'meio ambiente é tudo o que nos cerca', 'são as florestas com os rios, plantas e animais'. Essa percepção expressa uma visão essencialmente naturalista de meio ambiente, cujos elementos são essencialmente relacionados à denominada primeira natureza, ou natureza exterior (REIGOTA, 2010a, p.76).

Sob a ótica dessa representação naturalista dicotômica, nas últimas décadas, os paradigmas da disjunção (e.g MORIN, 1997) têm refletido ou mesmo se materializado no uso de elementos relacionados à dimensão ecológica da crise nos diferentes segmentos na sociedade. Esse fenômeno, orientado por uma percepção pautada na presença quase exclusiva de elementos da primeira natureza (REIGOTA, 2010a, p.76), vem sendo denominado "paradigma do verde", pelo qual "meio ambiente" e "natureza" são vistos como sinônimos e externos à nossa existência (PEREIRA 
\& LADVOCAT, 2010, p.72). No entanto, por imprimir um sentimento de não-pertencimento de nós, seres humanos, em relação à natureza, essa percepção constrói e banaliza a separação entre estes, gerando uma relação de dominação dos seres humanos sobre a natureza (GUIMARÃES, 2006, p.20).

Nessa linha de pesquisa, um estudo observou que não existe um consenso quanto ao conceito de meio ambiente na comunidade científica (REIGOTA, 2010a, p.11-15). A percepção de meio ambiente reflete os interesses científicos, artísticos, políticos, filosóficos, religiosos e profissionais de quem o idealiza (REIGOTA, 2006, p.21). Devido a esse caráter, a concepção de meio ambiente é considerada uma "representação social" (REIGOTA, 2010a, p.14), isto é, manifesta o senso comum, abrangendo os preconceitos, as ideologias e as características de atividades cotidianas relativas à percepção das pessoas (MOSCOVICI, 1976). Em análise profunda, as representações sociais equivalem a princípios construídos e partilhados por diferentes grupos societários, por meio dos quais compreendem, agem e transformam suas realidades (REIGOTA, 2010a, p.72). O caráter social das representações transparece na contribuição que elas exercem sobre os processos de formação de conduta e orientação das comunicações sociais (REIGOTA, 2010a, p.72).

Nesse sentido, nossa concepção de "meio ambiente" funciona como um referencial a partir do qual compreendemos e agimos sobre a realidade. Como nossas representações estão ligadas a questões puramente ecológicas, orientadas por uma perspectiva naturalista, a crise socioambiental se relaciona, então, à nossa concepção de meio ambiente. Uma percepção, em geral, fundada em dimensões paradigmáticas de separação entre os meios social e ambiental. Como consequência, tem-se hoje uma crise de um modelo capitalista de desenvolvimento e de sociedade, suas relações, suas percepções e representações. Uma crise caracterizada pela exploração desenfreada dos recursos naturais e orientada por um padrão de desenvolvimento produtivo que se reflete na própria sociedade, seu consumo, seu egoísmo, seus preconceitos e sua exclusão.

Dar conta desta complexidade é o real desafio da sociedade do século XXI. Um dos caminhos que tem sido explorados é a realização de processos formativos de Educação Ambiental que possibilitem debater as questões ambientais. No entanto, esses processos geralmente não contemplam práticas pedagógicas que problematizem as reais causas da crise (GUIMARÃES, 2003), e dão ênfase à discussão de problemas ecológicos. Um bom início para a realização de processos educativos que se pretendam ambientais é a discussão de conceitos básicos relacionados às questões socioambientais. Nesse sentido, já que nossa ação sobre o mundo resulta da maneira como o compreendemos (GUIMARÃES, 2010, p.62), a análise da percepção e do conceito de “meio ambiente" representa um bom ponto de partida para a realização desses processos (REIGOTA, 2006, p.21; REIGOTA, 2010a, p.14). Realizar experiências desse cunho com educadores adquire relevância, já que a 
partir de suas representações podemos caracterizar as práticas pedagógicas cotidianas desse grupo (REIGOTA, 2010a, p.72). O objetivo dessa pesquisa foi identificar e caracterizar as representaçóes sociais de professores, relacionadas à percepção de meio ambiente e inferir o reflexo das concepções observadas sobre a compreensão-ação desse grupo e suas práticas pedagógicas relacionadas às questões socioambientais.

\section{CAMINHOS METODOLÓGICOS}

Visando uma ação que possibilitasse discutir efetivamente as questões ambientais a partir da materialização de percepções e representações dos professores, a coleta de dados se deu por uma adaptação da metodologia proposta na oficina "Desconstruindo e Reconstruindo Representações Ambientais" (PEREIRA \& LADVOCAT, 2010). Essa oficina visa a estimular a desconstrução e a reconstrução conceitual acerca de representações sociais relacionadas a concepções de meio ambiente. Um processo necessário que, apesar de nada fácil, cada educador deveria ter ciência da importância para a sua ação pedagógica.

A oficina constitui-se de dinâmicas que envolvem a leitura de imagens, cores e palavras pelos participantes em relação às suas percepções e representações de "meio ambiente" e "natureza". A proposta da oficina é desenvolvida com base em uma perspectiva pedagógica dialógica, pela qual se consideram fundamentais as interações comunicativas que envolvem as pessoas em busca de um objetivo comum (REIGOTA, 2010a, p.26). Esse atributo representa um dos principais aspectos pedagógicos da Educação Ambiental (REIGOTA, 2010b) e no qual propostas educativas que se pretendam ambientais deveriam estar fundamentadas (REIGOTA, 2010a, p.26). Assim, a oficina se fundamenta em um método ativo, pelo qual os participantes do processo realizam experiências sobre o tema proposto, permitindo-se questionar dados e ideias, propor e apresentar soluções, sendo aberto e democrático (REIGOTA, 2006, p.38).

A coleta de dados foi realizada com professores do Ensino Básico do município de Itaguaí, estado do Rio de Janeiro, Brasil. A política de Meio Ambiente do município tem na educação ambiental um viés efetivo de atuação. Presume a conscientização permanente e sistemática da população, com adequação do ensino nos diferentes níveis, baseada no princípio de conscientizar-mobilizar

(ITAGUAÍ, 1990). Além disso, sua política ambiental prevê a incorporação dos princípios e objetivos da educação ambiental na escola e na comunidade, com vistas à conservação do meio ambiente (ITAGUAÍ, 1990). 
Com base nessa linha de ação, em junho de 2010, as Secretarias de Meio Ambiente e Educação \& Cultura de Itaguaí promoveram o I Fórum de Educação Ambiental do município, com o tema "Desafios, Reflexões e Práticas", evento no qual a coleta de dados foi realizada. O fórum teve como plano de fundo a instrumentalização de professores do Ensino Básico para desenvolvimento de uma práxis educativa capaz de formar alunos-cidadãos capazes de problematizar as questões socioambientais a partir das relações entre sociedade e natureza. Houve a participação de nove professores na oficina, dentre os quais três tinham formação em Ciências ou Biologia; um em História; um em Ciências Sociais; um em Letras; dois em Pedagogia e um Bibliotecário, com Ensino Médio completo.

Na primeira dinâmica, "Integrando imagens, contextualizando o tema", a partir de um conjunto de imagens, cada professor escolheu uma com a qual se identificasse. Posteriormente, os professores formaram grupos com base nas imagens que haviam escolhido e que julgassem estar relacionadas. As imagens pertenceram às seguintes categorias: "ambiente natural" com imagens de lagos, cachoeiras, florestas e animais; "sociedade" com imagens de diferentes atores - crianças, indígenas, população de rua, movimentos sociais; e "problemas ambientais" com imagens de lixão, queimadas, enchentes, desmatamento e poluição do ar. Essa dinâmica foi realizada com o objetivo de integrar os professores, formar grupos de discussão e contextualizar a proposta da oficina. Formaram-se três grupos. Em seguida, os professores apresentaram suas imagens, justificando o porquê da escolha e o que ela havia em comum com as imagens dos demais integrantes do grupo. Na sequência, cada grupo escolheu outra imagem dentre as que restaram. Essa escolha, posterior à formação dos grupos, simulou o consenso das representações individuais dos professores sendo, desta forma, uma representação coletiva de cada grupo.

Posteriormente, iniciou-se a dinâmica "Jogando com palavras, representando meio ambiente". Nessa dinâmica, foi pedido a cada grupo que, tendo em mente a concepção de "meio ambiente", selecionassem dez de um conjunto de trinta palavras. As palavras estavam reunidas em uma 'listade-palavras' ou um 'quadro-de-palavras'. Um dos grupos recebeu uma 'lista', e os outros dois grupos receberam o 'quadro'. Ambos os materiais, 'lista' e 'quadro', foram elaborados a partir das mesmas trinta palavras distribuídas em uma folha de ofício. As palavras contemplaram seis categorias: ambientes urbanos, biomas, animais, problemas sociais, problemas ecológicos e outros elementos (como sociedade, índio, saneamento básico). Essa dinâmica teve como objetivo identificar as representações dos professores por meio da materialização de suas percepções.

Visando a avaliar se, além do significado, a cor também influencia na tomada de decisão, no 'quadro' a cor das palavras variou entre azul, verde ou vermelho; já na 'lista', as palavras foram grafadas em preto e, após a seleção das mesmas, os professores as reescreveram em outra folha 
utilizando caneta de cor azul, verde ou vermelho. Essa etapa foi realizada com o grupo que recebeu a 'lista-de-palavras' visando a avaliar se o significado das palavras teria influência não apenas na escolha, como no caso do 'quadro', mas também na cor utilizada para a sua reescrita.

Na sequência, a fim de materializar as discussões e representações, cada grupo deu um nome para si e elaborou um cartaz para apresentação. Esse cartaz continha o nome dado ao grupo com as imagens e palavras selecionadas nas dinâmicas. Nas apresentações, os professores justificaram a relação entre as imagens que compuseram seus grupos, as palavras selecionadas e os respectivos nomes. Ao longo das apresentações, as problematizações e discussões da proposta da oficina foram conduzidas. Como sugerido por Guimarães (2010, p.62), realizando uma oficina de desconstrução de pré-conceitos para um processo de reconstrução conceitual em Educação Ambiental, o objetivo das discussões não foi apresentar uma infinidade de conceitos para aprofundamento; objetivou-se, sim, ressaltar como algumas concepções têm seus significados atrelados a uma visão de mundo que traduz o referencial paradigmático da sociedade e como seus sentidos, historicamente construídos, se estruturam e se refletem em nossa compreensão e em nossas ações sobre a realidade.

\section{AS PERCEPÇÕES AMBIENTAIS DAS PROFESSORAS}

Por meio da dinâmica de formação de grupos a partir das imagens, os três grupos de professores formados intitularam-se "Vida Harmônica", "Se você não preservar, o Planeta responderá" e "Sinfonia na voz da União, preservando a Cultura". Os resultados referentes à dinâmica do jogo de palavras estão apresentados na Tabela 1. 
Tabela 1. Palavras selecionadas por grupos de professores do Ensino Básico com base em suas percepções de "meio ambiente", ao longo da dinâmica Jogando com Palavras, Representando Meio Ambiente, Itaguaí, RJ, Brasil

\begin{tabular}{|c|c|c|c|}
\hline Categorias das palavras $^{(1)}$ & $\begin{array}{c}\text { Vida } \\
\text { Harmônica } \\
\end{array}$ & $\begin{array}{l}\text { Grupos de professores ---- } \\
\text { Se você não preservar, o } \\
\text { Planeta responderá } \\
\text { (3) }\end{array}$ & $\begin{array}{c}\text { Sinfonia da } \\
\text { voz na União, } \\
\text { preservando a } \\
\text { Cultura } \\
\end{array}$ \\
\hline Biomas & $\begin{array}{c}\text { Mata Atlântica, } \\
\text { Amazônia }\end{array}$ & Mata Atlântica & $\begin{array}{c}\text { Mata Atlântica, } \\
\text { Amazônia }\end{array}$ \\
\hline Problemas ecológicos & desmatamento & $\begin{array}{c}\text { desmatamento, } \\
\text { aquecimento global }\end{array}$ & $\begin{array}{c}\text { aquecimento } \\
\text { global }\end{array}$ \\
\hline Ambientes urbanos & $\begin{array}{l}\text { Itaugaíi }{ }^{(4)} \text {, escola, } \\
\text { Itacuruçá( }{ }^{(4)} \text {, casa, } \\
\text { jardim botânico }\end{array}$ & Itaguaí & Escola \\
\hline Problemas sociais & - & lixão, ganância, desperdício & $\begin{array}{l}\text { ganância, riqueza, } \\
\text { tráfico de drogas }\end{array}$ \\
\hline Animais & - & - & - \\
\hline Outros elementos & $\begin{array}{c}\text { saúde e } \\
\text { sociedade }\end{array}$ & $\begin{array}{l}\text { saúde, sociedade, } \\
\text { saneamento básico }\end{array}$ & $\begin{array}{l}\text { saúde, sociedade, } \\
\text { diversidade étnica }\end{array}$ \\
\hline
\end{tabular}

Não houve relações evidentes entre o número de palavras selecionadas com as respectivas cores. Esse resultado foi semelhante ao relatado por Pereira \& Ladvocat (2010, p.75), idealizando a metodologia aqui adaptada com educadores em formação. Os autores não observaram evidências claras entre o número de palavras selecionadas por cor. No caso da 'lista', da mesma forma, não foi observada tendência em relação à cor utilizada para reescrita das palavras. Já no que se refere à categoria semântica das palavras, os grupos selecionaram indistintamente "Mata Atlântica, Saúde e Sociedade", sendo "Amazônia, Desmatamento, Aquecimento Global, Itaguai, Escola e Ganância" elementos presentes em dois deles, não necessariamente os mesmos. Além disso, diferindo do resultado observado para a cor das palavras, para um dos grupos, foi observada relação entre a categoria semântica e o número de palavras selecionadas, sendo metade dessas de "ambientes urbanos".

Esses resultados iniciais demonstraram que as percepções ambientais dos professores, quanto ao conceito de meio ambiente, são bem fundamentadas e distantes de uma representação essencialmente "naturalista", segundo a qual meio ambiente é visto como sinônimo de natureza (REIGOTA, 2010a, p. 76). Entretanto, diferindo dessa dinâmica com as palavras, observouse manifestação paradigmática das percepções dos professores ao longo das apresentações que envolveram a leitura das imagens. 
O primeiro grupo a se apresentar foi o "Vida Harmônica". As imagens, a partir das quais se formou, relacionaram-se a ecossistemas naturais, a saber: um recife de coral, uma cachoeira, uma paisagem natural, composta de ambientes aquático e terrestre, e uma praia, sendo esta selecionada após as discussões iniciais do grupo. No cartaz elaborado, verificou-se que as imagens foram relacionadas por meio de setas, compondo um ciclo. Essa observação, paralela ao nome harmonioso dado em relação às imagens, sugere a tentativa de representar o equilíbrio da natureza. Essa inferência pôde ser corroborada ao longo da apresentação, na qual os professores explicitaram que aqueles ambientes 'representam a natureza que ainda está em equilibrio', pois não havia 'sinais da presença do homem'.

Essa representação "naturalista”, que foi expressa na ausência do ser humano (como ser social) como elemento constitutivo do meio ambiente (REIGOTA, 2010a, p.76), manifestou notadamente os paradigmas da disjunção (e.g MORIN, 1997). Em função da dicotomia que essa representação estabelece entre ser humano e natureza, ela leva-nos a encarar a nossa espécie como agente de destruição dos ecossistemas naturais. Equivocadamente, acreditamos que a manutenção intocada desses ambientes é a solução para o restabelecimento ou a conservação do equilíbrio, conforme demonstrado pelo grupo como "Vida Harmônica". Cabe ressaltar que esse equilíbrio é visto sob a ótica do equilíbrio de uma balança, estagnado, e não um equilíbrio dinâmico dotado de movimento e flutuações, isto é, dinâmico, como o que caracteriza os sistemas naturais.

Ratificando essa percepção limitada de meio ambiente como sinônimo de natureza, um dos professores manifestou-se dizendo que as imagens representavam 'ambientes ideais para se passar as férias' e nos quais ela 'gostaria de estar'. Uma representação que imprime a completa externalização do ser humano em relação à preterida natureza. Essa percepção vai de encontro ao observado na dinâmica do 'jogo de palavras', na qual cinco das dez palavras selecionadas pelo "Vida Harmônica” foram ambientes urbanos. Esse resultado demonstrou o quanto as representações de meio ambiente dos professores estão, na verdade, pautadas em percepções naturalistas, decorrentes de perspectivas cartesianas e antropocêntricas.

A influência da corrente cartesiana sobre nossas representações reside no fato de o método científico, ao separar uma parte da realidade para estudar (o objeto de estudo), especializa e fragmenta o conhecimento, o que gera uma tendência a se focar, cada vez mais, na parte em busca da dimensão da totalidade (GUIMARÃES, 2010, p. 64). Já o antropocentrismo, talvez um dos pressupostos mais fortes do cientificismo mecanicista, representa uma corrente historicamente construída pela qual nos vemos como centro dos processos do universo, adquirindo, pois, uma postura egocêntrica e individualista, tanto na compreensão do mundo, quanto em nossas ações nesse e sobre esse. 
Em função dessas perspectivas, os seres humanos se externalizaram da natureza, dificilmente se considerando um elemento integrante desta, mas como um ser a parte, observador-explorador (REIGOTA, 2006, p.11). Mais que exteriores, eles são vistos como excludentes (ARRUDA, 2000, p.284).

Desta forma, o contra-senso verificado entre a representação de meio ambiente a partir de ambientes antropicamente construídos (observada na dinâmica do jogo de palavras) paralela à perspectiva essencialmente naturalista (verbalizada pelo professor ao longo da leitura das imagens) demonstrou o quanto do antropocentrismo presente na primeira se refletiu na segunda. Além disso, essa contradição relacionou-se ao que Guimarães (2006, p.23) denomina "armadilha paradigmática”, pela qual os professores, em geral, manifestam uma compreensão limitada da problemática ambiental, que se expressa por meio de uma dificuldade discursiva e é informada por práticas baseadas em paradigmas da sociedade.

O segundo grupo a se apresentar foi o "Se você não preservar, o Planeta responderá". As imagens a partir das quais esse grupo se constituiu relacionaram-se a problemas de saneamento básico e habitação, isto é, algumas das consequências que compõem a crise, a saber: a imagem de uma comunidade submetida a enchentes e a outra de desmoronamentos e deslizamentos de terra que conduziram à tragédia no Morro do Bumba - catástrofe na qual deslizamentos de terra em uma antiga área de aterro sanitário (imprópria para habitação humana) no município de Niterói, RJ, ocasionou a morte de inúmeras pessoas e desabrigou várias famílias. Após as discussões, o grupo selecionou a imagem de uma queimada em área de pastagem para integrar às demais.

Antes mesmo da apresentação, pôde-se inferir quanto às suas representações relacionadas à questão ambiental. Em função apenas do nome "Se você não preservar, o Planeta responderá", foi perceptível o quanto as percepções dos professores estariam atreladas aos paradigmas da sociedade moderna, expressas por duas dimensões: a reprodução da noção de preservação como solução para a crise ambiental, dimensão esta que vem sendo largamente implementada no Brasil e nos países de terceiro mundo em geral (GÓMEZ-PAMPA \& KAUS, 2000, p.126), e pela revolta da natureza frente às ações maléficas do humano, que tem sido visto como ser destruidor. Ao longo da apresentação, o grupo ratificou essas hipóteses, manifestando que as imagens se tratavam de 'problemas ambientais', que são 'fruto das ações do homem sobre a natureza', ações essas demonstradas pela imagem da 'queimada'. No caso da enchente, os professores demonstraram noção de como a falta de planejamento urbano, somada à produção massiva de lixo pela população humana, pode resultar nessa questão. Da mesma forma, para a imagem do Morro do Bumba, verificou-se a percepção da relação existente entre as tragédias conduzidas e os problemas habitacionais envolvidos. Entretanto, a manifestação 
de que a natureza vem se revoltando contra a população humana e suas ações destrutivas foi evidente. Essa noção demonstrou o quanto as percepções dos professores são restritas e distantes de um significado mais complexo dos elementos e processos constitutivos da crise.

Alguns estudos envolvendo processos de formação em Educação Ambiental têm demonstrado resultados semelhantes. Investigando a percepção de problemas ambientais de professores que buscavam inserir as questões ambientais em suas práticas, Guimarães (2003) constatou a manifestação de uma compreensão limitada da realidade. Da mesma forma, Pereira et al. (no prelo) relataram como o modelo de separação entre os meios social e ambiental está presente na formação de professores e a compreensão-ação desse grupo. Nesse tema, por diversos momentos em disciplina de curso de Pós-Graduação em Educação Ambiental, Reigota (2010a, p.77) também observou que os professores enquadraram a espécie humana como "nota dissonante" do meio ambiente, um depredador por excelência.

Assim, a abordagem dada pelos professores do grupo "Se você não preservar, o Planeta responderá" foi contrária ao observado na dinâmica com o 'jogo de palavras'. Isso demonstrou o total reducionismo que caracteriza as representações sociais dos professores relativas à crise socioambiental, as quais foram tanto materializadas nos cartazes quanto informadas na dificuldade discursiva dos grupos. Esse contra-senso foi semelhante ao manifestado pelo grupo "Vida Harmônica" e ratifica a hipótese de que os professores caem e se prendem à armadilha paradigmática a partir de uma noção supostamente complexa da questão ambiental que, na verdade, é limitada. No entanto, essa percepção acrítica e não-relacional dos professores pode atrapalhar os objetivos de quaisquer projetos ou práticas de Educação Ambiental que visem ao estabelecimento e à melhoria de relações interpessoais e destas com o ambiente (PEREIRA \& LADVOCAT, 2010, p.76; PEREIRA et al., no prelo).

O terceiro grupo a se apresentar foi o "Sinfonia da voz na União, preservando a Cultura" que diferindo dos demais, teve o ser humano como elemento constitutivo de suas imagens, quais sejam: uma roda de capoeira, uma orquestra sinfônica, um casal de araras-azuis, uma tribo indígena e um movimento estudantil selecionado após as discussões iniciais. Face às imagens que o compuseram e a partir das quais o nome "Sinfonia da voz na União, preservando a Cultura" foi dado, como era esperado, que esse seria um grupo com concepções possivelmente distintas das dos demais grupos. A apresentação do grupo foi conduzida no sentido de demonstrar como os seres humanos, unidos, podem atuar como agentes de transformação social à busca de novos caminhos. 
Segundo o grupo, ao longo da história, muitos valores sociais têm se perdido no tempo bem como a relação entre a espécie humana e o ambiente. A partir dessa percepção, suas integrantes explicitaram que, atualmente, 'épreciso que atuemos em comunhão com o outro', numa coletividade, como um movimento social, cujos envolvidos, 'em favor de um objetivo comum, se associem para conquistá-lo', semelhante a um casal de araras-azuis, cuja interação no acasalamento possibilita a procriação da espécie. Nesse sentido, o grupo sugeriu que nos vejamos como uma 'orquestra sinfônica, cujos elementos trabalham em conjunto', com vistas a uma composição harmoniosa.

Essa noção de coletivo, visto não apenas pela soma de suas partes $(1+1=2)$, mas a partir da interação entre estas ( 1 com $1>2)$, tem por objetivo a percepção do todo, a noção de totalidade, nesse caso, da questão ambiental. Essa perspectiva, tida por Guimarães (2004) como uma abordagem sistêmica e denominada coletivo-conjunto, no sentido de um movimento conjunto e complexo decorrente da sinergia entre as partes, representa uma das mudanças de concepção necessárias à superação do modelo paradigmático vigente.

Assim, as representações do grupo "Sinfonia da voz na União, preservando a Cultura”, não estiveram fortemente arraigadas aos paradigmas da sociedade contemporânea, seu antropocentrismo, seu cartesianismo e reducionismos decorrentes. Pelo contrário, os professores desse grupo demonstraram umavisãocontextualizada, pelaqualossereshumanosforamrepresentadoscomoimportanteelemento doambienteeapartirdecujainteraçãopodeemergiroidealizadomovimentosocialcontra-hegemônico.

\section{CONCLUSÕES}

As representações ambientais dos professores aparentaram serem orientadas por uma perspectiva relacional e distante de concepções puramente relacionadas à natureza. Entretanto, em geral, verificou-se que essas representações iniciais, na verdade, se relacionaram à dimensão dicotômica dos paradigmas vigentes na sociedade, decorrentes de perspectivas cartesianas e antropocêntricas. Nesse sentido, "meio ambiente" e "natureza" foram tratados como sinônimos, denotando a real perspectiva que orienta os professores.

Essa percepção simplificada por parte dos professores ratificou a força que o modelo hegemônico de sociedade e seus paradigmas exercem em nossas instituições sociais, especialmente as de ensino, neste caso a escola. Por ocasião desse modelo, a escola que cursamos sempre teve uma prática baseada na reprodução de conteúdos em detrimento de uma práxis fundamentada no exercício da problematização e da construção de relações, sobretudo no que se refere às questõesecológicase sociais. Com relação à escola como espaço de formação da alunos-cidadãos capazes de realizar uma leitura 
crítica de mundo, os professores demonstraram o quanto e como suas práticas pedagógicas ainda são informadasporumacompreensãolimitadadaproblemáticasocioambiental.Essacompreensãodeveser superadaumavezquepodereforçarpráticasconservadorasemquaisquerprojetospedagógicosouações educativas que idealizem estabelecimento de melhores relações das pessoas entre si e com o ambiente.

\section{AGRADECIMENTOS}

Às Secretarias de Meio Ambiente e Educação \& Cultura do município de Itaguaí, RJ, que possibilitaram a realização desta pesquisa e aos professores pelas valiosas contribuições.

\section{REFERÊNCIAS}

ARRUDA, R. S. V. Populações tradicionais e a proteção dos recursos naturais em Unidades de Conservação. In: DIEGUES, A. C (org.) Etnoconservação, Novos rumos para a proteção da natureza nos trópicos. 2 ed. São Paulo: Nupaub-USP, 2000. 290p.

GÓMEZ-PAMPA, A. \& KAUS, A. Domesticando o Mito da Natureza Selvagem. In: DIEGUES, A. C. (org.) Etnoconservação, Novos rumos para a proteção da natureza nos trópicos. 2 ed. São Paulo: Nupaub-USP. 2000.290p.

GUIMARÃES, M. A Formação de Educadores Ambientais. Campinas: Papirus. 2004. 176p. Armadilha paradigmática na educação ambiental. In: LOUREIRO, C. F. B; LAYRARGUES, P. P. \& CASTRO, R. S. (orgs.). Pensamento Complexo, Dialética e Educação Ambiental. São Paulo: Cortez Editora. 2006. p.15-29.

. Construção conceitual em Educação Ambiental. 62-68p. In: CAMPOS, M.

L. \& FONSECA, L. C. S. (orgs.) Oficinas de Ensino - III Semana Paulo Freire na UFRRJ. Seropédica: EDUR. 2010. p. 62-68.

. Educadores Ambientais em uma perspectiva crítica - reflexões em Xerém

(Tese) Doutorado em Desenvolvimento, Agricultura e Sociedade. Seropédica: Universidade Federal Rural do Rio de Janeiro. 2003. 168p. 
GUERRA, F. M. Diálogo como caminho para uma nova organização curricular: a experiência de efetivação da Educação Ambiental no município de Angra dos Reis (Dissertação) Mestrado em Educação. Rio de Janeiro: Universidade Federal do Rio de Janeiro. 2008. 218p.

ITAGUAÍ. Lei Orgânica Municipal de Itaguaí. Texto da Lei de 02 de agosto de 1990. Câmara Municipal de Itaguaí, Estado do Rio de Janeiro. 1990. Disponível em < http:// www.camaraitaguai. rj.gov.br > Acesso em: 28 fev. 2011.

LADVOCAT, B. B. Trajetórias do curso de ciências biológicas da UFRuralRJ e sua materialização nas matrizes curriculares (Monografia) Graduação em Licenciatura em Ciências Biológicas. Seropédica: Universidade Federal Rural do Rio de Janeiro. 2010. 67p.

LEPSCH, I. F. Formação e Conservação dos Solos. São Paulo: Oficina de Textos. 2002. 177p. LOUREIRO, C. F. B. Trajetória e Fundamentos da Educação Ambiental. São Paulo: Cortez. 2004. 152p.

MORIN, E. Complexidade e ética da solidariedade. In: CASTRO, G.; CARVALHO E. A. \& ALMEIDA, M. C (orgs.). Ensaios de complexidade. 4.ed. Porto Alegre: Sulina. 1997. MOSCOVICI, S. La psychanalise, son image aet son publique. 2.ed. Paris: PUF, 1976.

PEREIRA, G. H. A., GUERRA, F. M., FONSECA, L. C. S. Percepções ambientais e crise civilizatória: as representações sociais de educadores em formação. In: FONSECA, L. C. S. \& GUIMARÃES, M. (orgs.) Educação em Ciências e Educação Ambiental: caminho e confluências. Seropédica: EDUR, 2012.

PEREIRA, G. H. A. \& LADVOCAT, B. B. Desconstruindo e reconstruindo representações ambientais. In: CAMPOS, M. L. \& FONSECA, L. C. S. (orgs.) Oficinas de Ensino - III Semana Paulo Freire na UFRRJ. Seropédica: EDUR, 2010. p.69-78.

PRIMACK, R. B. \& RODRIGUES, E. Biologia da Conservação. Londrina: Editora Planta. 2001. 371p.

REIGOTA, M. O que é Educação Ambiental. São Paulo: Brasiliense. 2006. 61p. . Meio Ambiente e Representação Social. 8.ed. São Paulo: Cortez. 2010a. 93p. 
A Educação Ambiental frente aos desafios apresentados pelos discursos contemporâneos sobre a natureza. Educação e Pesquisa, São Paulo, v. 36, n. 2, p. 539-553, 2010 b.

VIANA, V. M. \& PINHEIRO, L. A. F. V. Conservação da Biodiversidade em fragmentos florestais. Série Técnica, IPEF, v. 12, n. 32, p. 25-42, 1998. 